\title{
ESTUDOS
}

\section{A formação humana no horizonte da integralidade*}

Maurício Mogilka

Palavras-chave: prática educativa; subjetividade; formação integral; educação democrática; pedagogia

humanista.

\section{Resumo}

Apresenta o tema, o percurso desenvolvido e os resultados de uma pesquisa recentemente concluída. O tema da investigação foram os processos de formação integral do sujeito. Embora os vários paradigmas docentes surgidos no século 20, com orientações teóricas e ideológicas alternativas ao modelo tradicional, defendam ou ao menos sugiram uma educação integral, a estruturação metodológica desta formação tem se mostrado difícil, na teoria e na prática. Será tal dificuldade inerente à prática educativa? Será sempre necessário que uma prática privilegie uma dimensão na formação das crianças (cognitiva, afetiva ou social) em prejuízo das demais? Este é o problema central desta investigação, desenvolvida com os conceitos e reflexões da pedagogia humanista, especialmente o pensamento de Rousseau, Dewey e Rogers.

Sou um guardador de rebanhos.

O rebanho é os meus pensamentos.

E os meus pensamentos são todos sensações.

Penso com os olhos e com os ouvidos

E com as mãos e os pés

E com o nariz e a boca.

Fernando Pessoa

\section{$\mathrm{O}$ ancestral problema da formação integral}

A teorização didática na forma dos diferentes paradigmas de docência buscou incessantemente resolver, durante todo o século 20, algumas questões problemáticas que atingem as práticas pedagógicas, escolares ou não. Especialmente nos paradigmas que se apresentam com uma postura mais crítica em relação às contradições da sociedade existente, esta busca é bem visível. A escola nova, a educação anarquista, a pedagogia não-diretiva, as propostas de base marxista, a pedagogia freireana, embora com acentuadas diferenças em seus pressupostos teóricos e propostas de ação, têm tentado solucionar de diferentes formas problemas e questões muitas vezes semelhantes.

Um dos grandes problemas de qualquer teorização na área de práticas pedagógicas é o próprio fato de ela se constituir como uma teorização sobre a prática; portanto, sempre sujeita a uma distância entre as suas reflexões e a realização da prática. A não ser que adotemos uma compreensão de teoria e de prática baseada na racionalidade positivista, compreenderemos que esta última sempre extravasa as orientações teóricas, devido à sua complexidade e instabilidade. Contudo, este fenômeno não deve significar um desestímulo à teorização na área, pois se as práticas extrapolam a teoria, por outro lado toda prática estruturada está fundamentada em algum tipo de orientação teórica. Esta sempre exerce alguma influência, mesmo que indireta e parcial, sobre o campo pragmático. 
Outro problema da teorização na área de práticas pedagógicas e, por extensão, na pedagogia é o fato de as práticas ocorrerem em um contexto social e político que exerce forte influência nos fins, na estruturação e nos resultados de qualquer prática. Desta maneira, por mais consistente e crítica que seja uma teorização nesta área, seu objeto de estudo estará sempre em conexão com complicados fatores sociais, os quais, se podem ser analisados pelas formulações teóricas da área, não podem ser resolvidos por elas.

Pode a teorização didática prestar alguma contribuição à modificação das práticas, embora lhe escape o controle sobre o contexto onde estas ocorrem? A resposta a esta pergunta envolve uma tentativa de entender qual o grau de autonomia que as práticas pedagógicas e a ação dos sujeitos têm em relação às estruturas sociais que são o seu contexto. A análise desta questão - a articulação entre o micro e o macrossocial - constitui um importante passo metodológico para a análise do problema acima colocado.

Se estudarmos com atenção as inúmeras propostas didáticas alternativas dos últimos duzentos anos no Ocidente, veremos como as práticas por elas preconizadas freqüentemente enfatizam um determinado aspecto da estruturação dos alunos (cognitivo, afetivo ou político), colocando os demais em segundo plano. Esta dificuldade se origina não apenas do paradigma de ensino que orienta cada proposta, mas também de um fator que é inerente à estrutura das práticas pedagógicas: é realmente difícil articular estas três dimensões em uma mesma prática. Algumas dessas propostas alternativas, contudo, trazem em sua constituição - ao menos teoricamente - o conceito de educação integral, como percebemos em autores tão diferentes como Marx, Bakunin, Dewey ou Freinet. Mas a passagem do conceito teórico para a estruturação metodológica - campo privilegiado da didática - tem-se mostrado de difícil efetivação.

O tema central deste estudo consistiu exatamente na tentativa de investigar as possibilidades de as práticas pedagógicas promoverem a constituição cognitiva, afetiva ${ }^{1}$ e política dos educandos simultaneamente, isto é, se elas podem se constituir processos de formação integral. Como seria a conformação metodológica e relacional dessas práticas? Trata-se, portanto, de uma análise teórica das práticas pedagógicas, na perspectiva da construção de alternativas a estas práticas.
Esta investigação nasceu inspirada pelo desejo de vir a compor, se não um novo projeto pedagógico, pelo menos uma teorização rigorosa dos princípios metodológicos e relacionais que poderiam gerar, em futuro próximo e ao serem apropriados pelos agentes educacionais, novas propostas de prática. Entenda-se, contudo, que esta preocupação com a metodologia, se por um lado pretende mergulhar na tecnicidade necessária a qualquer prática complexa, nunca significa uma discussão meramente técnica e jamais um modelo de orientações para o que fazer.

O conhecimento da teorização sobre práticas pedagógicas e o acompanhamento constante de experiências alternativas realizadas em situação escolar e não-escolar, ${ }^{2}$ que eu venho realizando nos últimos doze anos, tem me mostrado que este enfoque - a geração de fórmulas para a prática - é bastante ineficaz. Ele enfrenta muita dificuldade para gerar soluções originais, pois, de forma geral, não é apropriado pelos sujeitos que o "utilizam". Por isto, aqui neste texto, metodológico significa não apenas uma forma de estruturar uma prática, mas de percebê-la e pensá-la: o termo é utilizado, portanto, no seu sentido original grego, com um significado que é distinto do termo técnica, esta sim, a forma prática de efetivar a dimensão metodológica, e sempre derivada dela.

Desta maneira, teorizar sobre os princípios metodológicos e seus possíveis efeitos envolve uma percepção das educadoras ${ }^{3}$ como sujeitos potencialmente capazes de pensar, sentir e perceber a sua prática de forma diferenciada dos modelos convencionais, e jamais como executoras de propostas pré-elaboradas.

O tema da investigação analisada neste artigo poderia ser sintetizado da seguinte maneira:

Como poderíamos, em uma perspectiva humanista, buscar os princípios que sustentariam, na dimensão metodológica e relacional, a construção de práticas alternativas, favoráveis ao processo de estruturação simultaneamente cognitiva, afetiva e política? É possível a alguma prática alcançar tal objetivo? É possível, então, a formação de sujeitos integrais em uma sociedade fragmentada em classes?

Logo, a intenção é analisar as possibilidades de constituição de práticas alternativas enfatizando a questão da aprendizagem nestas possíveis propostas e sua relação com o complexo problema da formação integral,

\footnotetext{
O termo afetividade, aqui neste artigo, é usado não apenas como sinônimo de sentimentos, mas de acordo com seu significado mais amplo, como é utilizado na psicologia ena filosofia. Neste caso, a dimensão afetiva inclui sentimentos e emoções, interesses, impulsos e tendências, além da vontade e dos valores da pessoa, que a dirigem voluntariamente para certos objetos e atividades e não para outros.

2 Utilizo aqui o conceito de práticas não-escolares em substituição ao conceito de práticas informais (pois toda prática tem uma forma), ou o conceito práticas educativas, pois nem todas as práticas não-escolares são efetivamente educativas, no sentido rigoroso do termo (Mogilka, 2003a).

A profissão docente é um campo predominantemente feminino, ao menos nos níveis analisados neste artigo: a escolaridade básica e a educação popular. Contudo, as nossas estruturas lingüísticas são conformadas pela milenar tradição machista que domina as sociedades de classe. Isto leva à masculinização de grupos femininos no discurso ou à anulação da presença feminina, silenciando o protagonismo das mulheres na sociedade, felizmente cada vez mais presente. Isto é conseqüência das rígidas divisões sociais em classes e gêneros, mas, dialeticamente, reforça estas divisões, ao apresentá-las à subjetividade, sutilmente, como naturais e inevitáveis. A superação da sociedade de classes depende da superação de todas as relações de dominação, inclusive o domínio sexista, seja no plano concreto, seja no plano da moral. Por isto, este artigo irá se referir aos grupos sociais de acordo com a predominância de gênero que nele houver.
} 
tão preconizada quanto escassamente obtida nas várias experiências alternativas. Este problema é especialmente grave em situações escolares, onde a expectativa de aprendizagem dos conteúdos disciplinares geralmente entra em conflito com o desenvolvimento das dimensões afetiva, política e até mesmo intelectual do aprendiz (uma vez que conhecimento e pensamento não são o mesmo fenômeno).

Será este conflito inerente à estrutura da prática pedagógica, isto é, atinge qualquer prática, em qualquer situação? Será, portanto, inevitável, provocando necessariamente a sobreposição de uma dimensão do desenvolvimento do aprendiz sobre as demais? Esta indagação nasce acompanhada da esperança de que a teorização possa lançar novas luzes sobre o trabalho pedagógico, talvez superando os impasses teóricos e metodológicos que hoje vivenciamos nesta área. Logo, o objetivo é analisar não apenas as condições em que se dá a ação pedagógica, mas, essencialmente, projetar novas possibilidades para esta ação, isto é, trata-se de uma intenção projetiva, voltada para o futuro e suas possibilidades.

\section{A relevância do tema: a articulacão entre subjetividade e política}

É quase uma unanimidade, segundo o enfoque dos diferentes paradigmas críticos de docência citados anteriormente, a ênfase na necessidade de mudança nas práticas pedagógicas. A teorização nestes paradigmas, embora com diferentes graus de radicalidade em suas proposições, tem procurado demonstrar como as práticas sociais que ocorrem nas escolas atuam como poderoso meio de controle social, isto é, têm um caráter político muito efetivo, embora nem sempre visível. Algumas pesquisas procuram indicar, inclusive, que os processos, conhecimentos e valores trabalhados nas práticas pedagógicas de forma sub-reptícia, ou seja, não declarada, podem representar um elemento formativo mais atuante do que o currículo formal, constituindo o que ficou conhecido como currículo oculto (Apple, 1989).

Em concordância com esta percepção, estes diferentes paradigmas têm buscado novas bases epistemológicas, metodológicas e, em alguns casos, relacionais, de modo a fundamentar propostas de intervenção que sejam bem-sucedidas, promovendo aprendizagem e formação educativa, porém fora do âmbito convencional. Pretende-se, assim e de forma diferenciada, superar os problemas de aprendizagem, proporcionando uma formação crítica e democrática. Contudo, como já foi afirmado, a geração de alternativas metodológicas com um mínimo de condições de efetivação nas situações reais é escassa em relação à produção teórica.

Parte desta dificuldade poderia ser atribuída, na minha interpretação, à ruptura teórica violenta que ocorreu em nosso país na reflexão didática dos anos oitenta: ao incorporar preocupações teóricas de cunho político progressista nas análises sobre as práticas - objetivo da maior importância social, sem dúvida -, a teorização pedagógica, e especialmente didática, secundarizou fortemente as tradições humanista, construtivista e tecnopedagógica. Isto criou um vácuo metodológico gravíssimo, pois o pensamento crítico não possuía arcabouço teórico para lidar com estas questões, apesar da sua competência para desenvolver as análises sociopolíticas.

Contudo, o aspecto metodológico de uma prática não está dado automaticamente, desde quando se definam os fins políticos e formativos desta prática. A dimensão metodológica não nasce espontaneamente, mas exige intenso e apropriado trabalho intelectual, para gerar, a partir dos valores e objetivos daquela proposta e das condições contextuais, formas específicas e coerentes de ação. Exige, portanto, que se entre no mérito da questão. Ao contrário do que ocorreu no Brasil no início dos anos oitenta, o trabalho de teorização sobre a prática pedagógica desenvolvida nos Estados Unidos e na Europa Ocidental nos últimos anos e recentemente incorporada pela produção brasileira deu, de diferentes formas e em diferentes abordagens teóricas, uma especial atenção às questões metodológicas e subjetivas presentes nas práticas.

A subjetividade dos agentes envolvidos, a forma de o professor pensar e representar a prática, a relação entre afetividade e aprendizagem, a qualidade das relações interpessoais estabelecidas e a estruturação metodológica da prática e seus efeitos estão, em diferentes níveis e graus de importância, presentes em abordagens e paradigmas recentes de investigação e/ou formação docente, como o chamado paradigma da prática reflexiva (cf. 
Shöm, 1995; Zeichner, 1995; Sacristán; Pérez Gómez, 1998), o paradigma da formação clínica de professores (cf. Perrenoud, 1993) ou, ainda, as recentes tentativas de construção de uma teorização didática a partir do construtivismo, como em Zabala (1998) ou Coll (1996)

Portanto, a relevância do tema aqui analisado poderia ser justificada pela importância destas questões metodológicas e subjetivas para a construção das práticas alternativas, ou seja, práticas que consigam cobrir (se isto for possível) os três diferentes e interligados campos da formação humana - cognitivo, afetivo, político - nas condições sociais vividas em nosso país. Longe de ser uma problemática já resolvida pelas mais recentes teorias, esta questão é de uma grande atualidade, em virtude do próprio fato de não se ter ainda alcançado em nossa sociedade um suficiente grau de autonomia dos atores sociais que permita um suporte político para os projetos realmente democráticos de sociedade. Este problema perdura além e apesar de todo o desenvolvimento das tecnologias da informação, pois os efeitos políticos destas dependem de como elas são apropriadas socialmente e com que fins.

A formação integral aqui é vista como uma possibilidade de superar a semiformação proporcionada pelo modelo unidimensional de prática, característico da cultura capitalista, onde as elites são obrigadas, como resultado de conquistas históricas, a conviver com grande porcentagem da população na escola, fenômeno que não era enfrentado pelas elites medievais, por exemplo. Neste contexto social, a formação se reduz a uma semiformação, excessivamente centrada na dimensão cognitiva e racional (mas não reflexiva). $\mathrm{Ou}$ seja, racional no sentido instrumental, voltada para fins produtivos e imediatos, e não para a reflexão ampla e crítica da realidade. Esta semiformação depurou a cultura do seu possível caráter formativo, humanizador e emancipatório (Giroux, 1983, 1986; Adorno; Horkheimer, 1985).

Este modelo, em articulação com outras estruturas sociais conservadoras, favorece a produção de subjetividades fragmentadas, devido à negação ou subestruturação de importantes dimensões do sujeito. Tal subjetividade é menos resistente ao domínio e à hegemonia, pois é mais frágil a sua integração consigo mesma, com sua comunidade e com o contexto onde vive. No atual contexto social e cultural, como se colocam, então, os processos pedagógicos de formação do sujeito, escolares e não-escolares? Podem os mesmos se constituir em potentes estratégias sociais para a formação de subjetividades ativas e democráticas?

\section{O suporte teórico: uma teoria polêmica}

O suporte escolhido para desenvolver o tema é uma abordagem teórica com forte presença nas formulações didáticas no século 20: a pedagogia humanista. A minha intenção foi utilizá-la para entender o problema, mas também atualizá-la, mostrando a sua vitalidade. Esta abordagem teórica forneceu o suporte para as questões de fundo da temática, como a concepção de sujeito, de conhecimento e de sociedade, especialmente pelo seu vigor na fundamentação de um conceito democrático de sociedade, desde Rousseau. Mas, por se tratar de uma filosofia da educação, esta abordagem oferece também os conceitos e reflexões que tematizam a própria prática docente. Ela contribuiu também no âmbito das questões diretamente metodológicas e subjetivas destas práticas, ao mergulhar nas suas difíceis questões de estruturação fora dos modelos convencionais.

A pedagogia humanista tem sido lida com acentuada resistência por uma parte dos autores da pedagogia política, especialmente aqueles ligados a uma visão mais estruturalista ou materialista ortodoxa. Segundo estas análises, os autores humanistas careceriam de uma visão "política" e crítica de educação. Contudo, em outros países, autores reconhecidamente críticos reconhecem o potencial democrático de autores humanistas, e os articulam com suas referências de origem. Pedagogos como Michel Apple (Apple; Beane, 1997) ou Henry Giroux (1997), por exemplo, são leitores de John Dewey.

No tema específico analisado neste artigo, uma investigação diretamente realizada nas fontes humanistas - e não apenas em comentadores - tem demonstrado o potencial crítico e alternativo desta abordagem. O que parece ser realmente uma contradição de alguns pedagogos humanistas está na dificuldade de este pensamento realizar de forma mais ousada a articulação micromacrossocial. O pensamento de Dewey, contudo, não parece apresentar esta contradição, como tentarei mostrar a seguir. 
A pedagogia humanista é também um importante suporte para a análise de aspectos subjetivos inerentes às práticas, principalmente se entendemos que estas são sempre, mesmo que de forma distorcida e alienada, práticas de formação da subjetividade. Os autores mais utilizados para trabalhar o tema foram Rousseau (1978a, 1878b, 1996), Dewey (1944, 1952, 1953, 1958, 1970, 1979a, 1979b, 1980a, 1980b, 1980c, 1980d, 1980e, 2001) e Rogers (1978, 1983, 1985, 1991, 1992).

Especialmente o pensamento social de Dewey representa, na minha percepção, um suporte muito adequado para fazer mais diretamente as associações entre práticas pedagógicas, educação e estruturas sociopolíticas. O pensamento desse autor, dentro das várias linhas da pedagogia humanista, é o que apresenta maior vigor na análise das relações entre política e processos educativos. Por outro lado, Dewey desenvolve suas reflexões políticas em um horizonte teórico mais extenso do que as correntes críticas deterministas. Desta forma, esta filosofia social contribui para realizar as articulações citadas sem incorrer em perspectivas reducionistas que estabeleçam uma hierarquia entre educação e estruturas políticas.

O trabalho intelectual desse autor, considerado hoje, ao ser relido, uma verdadeira filosofia da democracia radical, se caracteriza pela intenção de estabelecer um discurso teórico e metodológico que consegue ser crítico e fazer uma análise sociológica da educação sem, contudo, dissolver as questões subjetivas e culturais que constituem a própria estrutura das práticas e relações pedagógicas. Desta forma, há aqui uma tentativa de superação dos impasses e limitações das teorias deterministas sobre a relação educação-sociedade, sem recair, contudo, em uma análise colada ao liberalismo conservador, que projeta a liberdade do sujeito para uma esfera metafísica. Por isto, esse autor se constitui um adequado apoio para trabalhar com as questões da singularidade, especificidade, indeterminação e conflito de valores, sempre presentes nas práticas pedagógicas e sempre associadas com suas conotações políticas.

Dewey realiza uma tentativa, a partir do pragmatismo norte-americano e de uma visão interacionista de sujeito, de articular os aspectos subjetivos, singulares e relacionais da prática educativa com a ação das estruturas sociais dominantes. Ele busca mostrar como a chamada educação tradicional planta suas sementes na subjetividade da criança, para produzir futuros adultos conformados e pouco participativos. Isto, para o autor, é um obstáculo grave para a construção de qualquer proposta democrática de sociedade. A democracia radical, para Dewey, está baseada em uma vida fortemente participativa e intensamente comunicada. Por isto, tal projeto social depende fortemente do elemento subjetivo. $\mathrm{O}$ trabalho desse autor envolve, portanto, a intenção de estabelecer a conexão micromacrossocial, embora ele não use explicitamente este conceito.

Um outro questionamento importante que é feito à pedagogia humanista reside nas suas ligações com a ciência clássica; Dewey, inclusive, é tido por alguns autores como um pensador positivista. Daí o questionamento: estas propostas de formação democrática não estão dentro dos marcos da ciência ocidental? A ciência não é uma estrutura de legitimação da ordem social? Além disto, como falar em formação integral baseado na ciência, se ela fragmenta e divide?

Os autores com os quais estou trabalhando aqui são Rousseau, Dewey e Rogers. Nenhum deles, na minha percepção, está dentro dos marcos da ciência ocidental, nem no seu sentido estrito (positivismo) nem no sentido mais amplo. No caso de Rousseau, temos um filósofo que contesta em grande parte os proclamados avanços sociais que seriam trazidos pela ciência e pela tecnologia, enfrentando abertamente as principais teses do Iluminismo (embora Rousseau não rejeite integralmente as contribuições deste movimento filosófico). As desconfianças do autor suíço com respeito à ciência ficam bem patentes no seu Discurso sobre as ciências e as artes, que ganhou em 1750 o prêmio da Academia de Dijon. À pergunta: O restabelecimento das ciências e das artes terá contribuído para aprimorar os costumes?, Rousseau responde radicalmente em seu Discurso: não.

Quanto a Dewey, trata-se de um autor que respeita e valoriza a ciência, mas de forma crítica e relativizada. Além do estilo poético de fazer filosofia, presente em muitas de suas obras, como Experiência e nature$z a$, a sua busca por uma radicalidade experiencial para a filosofia o leva a uma das mais poderosas críticas às filosofias especulativas. Sua percepção integral da realidade o leva a tratar estética e educação de forma conjunta, assim como fé e democracia. Juntamente com seu estilo poético, Dewey nos apresenta em muitas de suas obras uma visão cósmica e espiritualizada 
da realidade. Em muitos pontos, seu discurso apresenta semelhanças com as grandes narrativas espirituais, como a cosmologia grega, os textos védicos e o taoísmo. É possível, inclusive, demonstrar paralelos entre as concepções deweyanas e a filosofia do Tao (Dewey trabalhou dois anos no Japão e na China, entre 1919 e 1921). ${ }^{4}$

Dewey também será um dos autores responsáveis pela arrancada pragmatista, que retira a ciência do âmbito epistemológico e a atira no campo da política, sendo por isso reconhecido como um precursor, sob um certo aspecto, do pós-estruturalismo. Só para se ter uma ligeira idéia da forma como Dewey concebe a atividade humana de geração do conhecimento, ele se refere às técnicas de pesquisa científica como operações existenciais, devido ao grau de envolvimento pessoal e político que os pesquisadores têm na produção dos saberes. Podemos chamar um autor assim de positivista?

Carl Rogers teve a sua formação inicial marcada pela ciência clássica, pela escola nova e pelo existencialismo. Ao longo de sua carreira intelectual (ele escreveu incessantemente entre 1930 e 1987) irá agregar estas referências a outras, inclusive os autores ligados às linhas mais divergentes da ciência ocidental, como a física quântica. Posteriormente, irá integrar ao seu trabalho intelectual, clínico e social vários princípios das filosofias do Extremo Oriente, como o taoísmo. Rogers participará intensamente do movimento do potencial humano, que explodiu na década de sessenta, associando princípios das psicologias ocidentais com aqueles de origem oriental, como o zenbudismo, buscando uma integração entre mente e emoções, ciência e espiritualidade, pessoa e comunidade.

Finalmente, um terceiro questionamento feito à pedagogia humanista está baseado na suposição de que se trata de uma teoria ultrapassada, pois foi gerada em um outro contexto histórico. Ora, o respeito à história e às mutações de época a época nos levam a ter uma saudável atenção com a especificidade de cada tempo e os seus problemas sociais. A filosofia política de Hegel e Marx foram importantes discursos para afirmar esta perspectiva nas ciências humanas em geral e nas ciências sociais em particular.

Contudo, uma perspectiva de respeito à história precisa ser tomada com equilíbrio, para evitarmos cair no extremo oposto das abordagens idealistas ou liberais, que perdem o senso da relatividade histórica; ou seja, para evitarmos reduzir tudo à história e perdermos o senso daquilo que permanece: as estruturas. Estas evidentemente também mudam. Aliás, tudo muda, pois o cosmos está em permanente movimento, e nada permanece como é para a eternidade. Mas algumas estruturas - como as genéticas ou a estrutura física da matéria - mudam tão lentamente que suas alterações são pouco perceptíveis em um período de milênios.

Também as estruturas políticas e culturais, especialmente no que elas têm de mais íntimo na sua relação com a subjetividade, mudam na sua forma externa, mas se alteram pouco no que têm de essencial. A estrutura básica da relação de dominação-submissão, por exemplo, mudou muito pouco no espaço de décadas, e até mesmo de séculos. Os dominadores aprendem formas mais sofisticadas e ágeis de controlar, e aqueles que ocupam uma posição de subordinação encontram formas adaptativas de viver a situação da maneira mais inteligente e confortável que lhes seja possível. Mas a essência deste tipo de relação, a sua estrutura íntima, permanece muito semelhante.

Trabalhando na área social há mais de dez anos, tenho percebido como é fácil, no trabalho comunitário, o trabalhador social e as lideranças reproduzirem com as comunidades (e as comunidades conosco) as mesmas características estruturais das relações autoritárias ou paternalistas que elas vivenciavam com o poder público ou econômico. Ou seja, como podemos, sem perceber, substituir a tutela anterior pela nossa. Esta tendência é bem visível quando a comunidade ou grupo não vivenciou anteriormente experiências consistentes de autonomia e quando os profissionais e a concepção do projeto assumem atividades e responsabilidades que deveriam caber à comunidade.

Mas o que isto tudo tem a ver com a questão da atualidade da pedagogia humanista? Primeiramente, este modo de olhar - percebendo o que muda e o que permanece - nos mostra que, no espaço de décadas, e ainda dentro da sociedade capitalista, alguns problemas continuam. Algumas das problemáticas que Dewey e seus colaboradores tentaram resolver através de reflexões e experiências práticas realizadas na primeira metade do século 20, por exemplo, são muito semelhantes àquelas que ainda tentamos solucionar hoje. E isto porque estas problemáticas estão ligadas a questões estruturais.

\footnotetext{
4 Não é intenção deste artigo demonstrar os paralelos entreopensamento de Dewey e as filosofias do Extremo Oriente, como o taoísmo e o budismo. Apenas para exemplificação, podemos analisar isto em Democracia e educação, no capítulo treze, sobre a natureza do método, quando o autor explica a retitude e a atividade integrada. Estou cada vez mais convencido de que Deweyé zen em muitos aspectos da sua filosofia e da sua maneira de encarar o cosmos.
} 
Eu gostaria muito de admitir que a pedagogia humanista não serve mais para analisar os problemas que hoje enfrentamos em nossas práticas escolares, pois isto significaria que os problemas que esta abordagem havia detectado e tentado resolver já foram solucionados. Mas não é assim que a realidade escolar tem se mostrado. Com freqüência, a minha experiência e a de outros colegas, realizadas semanalmente nas escolas públicas, têm demonstrado problemas e conflitos muito semelhantes àqueles descritos e analisados, por exemplo, no pequeno livro publicado por Dewey em 1938, Experiência e educação.

Os problemas de disciplina, a ansiedade das professoras, a inquietação e sofrimento das crianças, a dicotomia entre o programa escolar e a vida vivida, as saídas autoritárias ou permissivas, a dificuldade de estabelecermos as bases de uma autoridade democrática - todas estas problemáticas - têm uma grande semelhança com aquelas descritas nessa obra. E isto ocorre porque se trata de um estudo estrutural, isto é, que atinge a estrutura do ato pedagógico e da sociedade onde se dá este ato.

Um outro argumento que justifica e demonstra a vitalidade dessa teoria ainda hoje é o fato de ela estar presente, de forma secreta ou explícita, em teorias muito atuais, como o construtivismo. Isto se torna bem claro quando analisamos as relações entre o pensamento de Piaget e a Escola Nova. As semelhanças entre as experiências atuais, nas escolas inspiradas pela epistemologia genética e seus desdobramentos pedagógicos, e as anteriores experiências da educação ativa se devem ao fato de Piaget ter sido profundamente influenciado pela escola nova. Como se sabe, o autor suíço não era um pedagogo, e nem o ensino era sua principal preocupação. Apenas duas entre suas obras de grande circulação, Para onde vai a educação?, publicada em 1948, e Psicologia e pedagogia, de 1969, são dedicadas à educação enquanto educação.

Mas Piaget, especialmente preocupado com os processos de aprendizagem humana, irá influir muito na educação do século 20, por intermédio de autores como Ausubel, na década de sessenta, e César Coll e o grupo de Barcelona, a partir da década de oitenta. Estes autores transpuseram para a área didática muitas descobertas e princípios teóricos da epistemologia genética.

Piaget, inicialmente um biólogo e posteriormente um epistemólogo, sofreu muita influência dos pedagogos da Escola Nova: Jean-Jacques Rousseau, Pestalozzi, John Dewey, Edouard Claparède (que o trouxe para trabalhar junto de si, a partir de 1921), Maria Montessori (por quem tinha grande respeito), entre outros. Estas influências são reconhecidas pelo próprio Piaget, especialmente nas duas obras acima citadas. Isto certamente explica as semelhanças entre as escolas ativas atuais, de base construtivista, e a Escola Nova.

\section{O percurso metodológico desenvolvido}

O caminho metodológico dentro de uma pesquisa desta natureza só se define plenamente no próprio percurso investigativo, em contato com o tema vivo a ser pesquisado e por ele alimentado. Não cabia, portanto, um profundo detalhamento na proposta inicial, pois seria um esforço artificial e contraditório com a atitude intelectual e com os fundamentos que sustentaram esta investigação. É necessário explicitar que se tratou de uma pesquisa teórica, ainda que voltada para um tema da prática social.

Contudo, isto não excluiu a busca do apoio em fontes empíricas que serviram para balizar e relativizar as reflexões e conceitos teóricos. Estas fontes se constituíram, nesta investigação, a partir de duas origens: os resultados de pesquisas empíricas e a minha própria experiência docente, inicialmente como professor do ensino fundamental e médio e atualmente nos cursos de formação de professores, em contato constante com as práticas pedagógicas. Outro suporte empírico veio da minha experiência em extensão, trabalhando há alguns anos em projetos e movimentos sociais, em contato constante com práticas de educação não-escolar.

Esta experiência provocou em mim a busca de um diálogo entre as práticas escolares e as não-escolares, tentando entender de que maneira estas últimas podem iluminar novos horizontes para os complexos problemas da didática escolar. Contudo, o contrário também se verifica: as práticas escolares e a tentativa de gerar alternativas para elas têm possibilitado importantes contribuições ao entendimento das práticas em movimentos e projetos sociais de educação. Isto se dá porque a leitura realizada sobre estas práticas tem se fundamentado em referências alternativas aos modelos convencionais. 
Tal leitura aproxima práticas que de outra forma pareceriam distantes: torna perceptível que a estrutura básica destas atividades é a mesma.

A articulação das dimensões micromacrossocial se constitui um importante passo metodológico para o desenvolvimento desta investigação teórica. É justamente o seu esclarecimento que permite transitar com alguma segurança pelo instável e singular território das práticas, investigando os seus aspectos subjetivos e metodológicos sem desvinculá-los das condições e estruturas sociais. A investigação sobre a articulação citada se constitui difícil exercício intelectual, escassamente obtido tanto pelas pedagogias de orientação funcionalista como por aquelas de inspiração materialista. Contudo, igualmente, as teorias pedagógicas orientadas pelas sociologias centradas na dimensão microssocial, como o interacionismo simbólico e a Nova Sociologia da Educação (especialmente em sua primeira fase), têm dificuldades de estabelecer os nexos entre as duas dimensões (Coulon, 1995).

A rica vertente da pesquisa qualitativa em educação, de caráter etnográfico e antropológico, representa, nos últimos anos em nosso país, uma saudável tentativa de investigar as práticas escolares sem recair em análises por demais estruturais e deterministas, que muitas vezes desconhecem ou não enfatizam suficientemente a riqueza e complexidade de cada prática específica. Indiretamente influenciadas pela fenomenologia e pelo interacionismo simbólico, essas investigações empíricas de natureza etnográfica e "ecológica" têm demonstrado a importância de elementos singulares, subjetivos e relacionais nos processos e nos resultados destas práticas.

Como todo trabalho que analisa uma dimensão singular da realidade social, seja ele de natureza empírica ou teórica, estas abordagens sempre estão sujeitas ao risco de, mergulhando e descrevendo o específico, não conseguir em alguma etapa da pesquisa fazer as necessárias conexões com as dimensões estruturais que deixam, muitas vezes invisivelmente, as suas marcas no singular. Para evitar este risco, torna-se necessário neste tipo de investigação o cuidado metodológico de buscar as citadas conexões, em um esforço que necessita de intensa atividade interpretativa, com adequado apoio teórico. Assim, o método de investigação mais adequado parece ser um processo contínuo de diálogo entre o singular e o geral, o institucional e o estrutural. Desta forma, podemos criar possibilidades de alcançar a difícil articulação micro-macrossocial.

O interessante nesta proposta metodológica é a possibilidade de realizar a investigação em várias direções ao mesmo tempo, sem cair em determinismos do estrutural sobre o singular e o subjetivo - o que anularia as possibilidades de emancipação e o próprio devir histórico -, mas também sem negligenciar a força que as estruturas existentes exercem sobre os agentes e instituições educativas, isto é, sem retornar para uma análise liberal ou metafísica (no sentido negativo da palavra). A pedagogia humanista, especialmente no pensamento de John Dewey, mostrou-se um referencial adequado para realizar esta intenção metodológica.

Outro aspecto metodológico importante diz respeito ao fato de que, se observarmos com bastante atenção, ao falar de formação integral da maneira como aqui está sendo definida, perceberemos que este fenômeno nada mais é do que o educar, educere: formação integral e educar são uma só e a mesma coisa. Logo, a resposta à pergunta como favorecer uma formação integral? depende da resposta a uma pergunta anterior: o que é educar? Desta forma, o problema desta investigação, definido anteriormente, pode ser colocado de uma forma ligeiramente diferente sem deixar de ser o que é: Podem as práticas pedagógicas se converter em práticas educativas na realidade em que vivemos? E se isto for possível, como poderia ser estruturado na prática? ${ }^{5}$

Educere, como era entendido pelos antigos, significa a experiência que desenvolve as potencialidades da pessoa, estrutura produtivamente o eu e, portanto, parece implicar um processo de formação mais amplo e mais integral do que aquele que se obtém com o ensino dos conhecimentos. Mas a palavra educere representa uma prática que, mesmo sendo muito antiga, está parcialmente oculta na modernidade; daí os termos educar e ensinar serem com freqüência tomados como sinônimos. Mas será o processo educativo redutível ao ensino de conhecimentos? É neste sentido rigoroso que o termo educar foi tomado como objeto desta investigação. O que podemos afirmar sobre isto hoje, em pleno capitalismo? Há ainda validade nesta discussão? Que contribuições traz a pedagogia humanista para temática tão complexa?

\footnotetext{
5 Aqui o termo práticas pedagógicas é tomado no sentido amplo, envolvendo qualquer prática sistemática, escolar ou não, onde ocorra algum processo de ensino eaprendizagem de conhecimentos. Inclui, portanto, desde uma simples prática de ensino até as práticas mais elaboradas e complexas, como as educativas plexas, como as educativa (Mogilka, 2003a)
} 
Acima foi afirmado que a investigação apresentada neste artigo foi um estudo inicialmente aberto, isto é, pretendeu encontrar o seu método, o seu caminho, no próprio caminhar. Embora já tivesse o seu tema e o seu sustento teórico definido, ele iniciou-se aberto, receptivo, pleno de possibilidades quanto ao percurso a construir. Esta atitude fenomenológica (no sentido amplo da expressão) favorece a construção de novos significados e novas soluções para o urgente e ancestral problema da formação integral.

Contudo, isto não impediu que se projetasse, de forma precária e bastante flexível, uma seqüência metodológica para a pesquisa. Este exercício imaginário, mesmo sendo alterado com o desenvolvimento da investigação, representou saudável tentativa de fazer uma reflexão sobre as possibilidades do percurso a ser desenvolvido. Afinal, não é isto que significa o termo metodologia? Esta seqüência metodológica foi definida em seis momentos, que passarei a apresentar a seguir.

O primeiro momento foi a proposta da investigação, com o seu tema, seu apoio teórico, seus problemas. Trata-se, portanto, do próprio projeto, com as modificações que o tempo mostrou necessárias.

O segundo momento consistiu numa discussão aprofundada sobre o que é a pedagogia humanista, base teórica da investigação. Neste momento, além de uma contextualização histórica, foi necessário desenvolver alguns conceitos fundamentais desta abordagem teórica: a sua concepção de sujeito e de natureza humana, o conceito de desenvolvimento, a sua compreensão da relação sujeito-sociedade, a articulação micro-macrossocial, o conceito de experiência e, finalmente, o conceito do que é educar, no sentido rigoroso do termo, cuja compreensão foi essencial para esta investigação. A intenção aqui foi demonstrar as características básicas desta abordagem e preparar os conceitos para o uso que eles tiveram nas etapas seguintes, ao mergulhar no tema da investigação.

O terceiro momento analisou as relações entre educação e vida democrática. Aqui a intenção foi trabalhar as conexões entre as condições sociais mais amplas e as práticas educativas. Embora navegue por um trajeto nitidamente não-determinista, a filosofia política que está subjacente à pedagogia humanista sempre leva em consideração o contexto social na análise de qualquer evento singular. Isto se explica pelo seu caráter interacionista, visível principalmente em autores como Dewey, com uma sólida concepção de sociedade e uma vigorosa utopia social - a sociedade democrática.

Dewey pensa uma educação plenamente democrática em uma sociedade democrática, diferente do modelo de democracia vigente: trata-se de uma democracia radical, um modo de vida compartilhado, e não apenas uma forma de governo. Mas o autor sustenta um certo otimismo nas possibilidades de a educação, transformada, transformar a sociedade. Há aqui uma dialética e uma contradição, que parece ser fecunda em novas idéias e soluções pragmáticas para se compreender a relação educação-sociedade. Podese constituir práticas de formação integral "produtoras" de subjetividades capazes de mudar as estruturas? Podem as estruturas ser modificadas pelas coletividades organizadas, em pleno capitalismo?

O quarto momento se constituiu em algo que poderíamos chamar de "epistemológico". A intenção foi conectar as discussões precedentes com uma reflexão do que é o pensar e o conhecer, segundo a pedagogia humanista. Aqui eu tentei demonstrar as conexões entre o pensamento, o conhecimento e a ação, e entre desejo, interesse e aprendizagem. Desponta aqui uma característica singular da concepção de conhecimento da pedagogia humanista, já presente em Rousseau no século 18: o pensamento e a geração de conhecimentos são entendidos como indissociáveis da ação e da paixão.

Trata-se, portanto, de uma concepção estética e erótica do conhecer e do pensar, bem diferente da noção moderna de razão. Tal noção prevaleceu durante grande parte da modernidade e vem sendo sistematicamente demolida, desde o século 19, por autores tão diferentes como Schopenhauer, Nietzsche ou Marx. Contudo, ainda é grande a sua força nos processos de formação atuais, comprometendo a suas possibilidades de formação integral, pois esta concepção de conhecimento desvincula desejo e aprendizagem, corporeidade e intelecto. $\mathrm{Na}$ verdade, tal concepção parece ainda fundamentar boa parte dos modelos de subjetividade existentes; e das possibilidades reais de sua superação depende, em parte, a constituição de práticas de formação integral.

O quinto momento consistiu numa discussão sobre a relação entre práticas educativas e os processos de formação humana; aqui a investigação tentou concluir a 
trajetória proposta. Ao abordar a formação humana e quais as condições da sua realização, tornou-se possível dialogar com o caráter desta formação: uma formação fragmentária humaniza? O que é e em que condições se dá isto que nós, na modernidade, chamamos de "humano"? Quais as relações entre uma formação fragmentária - uma semiformação, como diz Adorno - e as estruturas sociais do mundo capitalista? Há qualquer condição real e efetiva (e não "inventada" no nível teórico apenas) de subverter os dolorosos e desumanos processos de formação presentes naquilo que nós chamamos de pedagogia tradicional? Aqui nós voltamos à questão inicial, fechando o ciclo da investigação.

O sexto momento deste trabalho consistiu nas conclusões de todo o percurso desenvolvido, representando uma síntese do processo intelectual. A intenção foi fazer um fechamento com caráter reflexivo; contudo tais conclusões devem ser encaradas aqui como resultados precários, instáveis e sempre sujeitos a novas perguntas, dentro de uma inspiração heideggeriana: uma resposta só guarda sua força de resposta enquanto permanece enraizada no questionamento. São estas conclusões instáveis que serão apresentadas a seguir.

\section{Conclusões alcançadas}

A formação integral é imprescindível à constituição de uma educação democrática, uma vez que os processos sociais nãodemocráticos, todos eles, se sustentam em modelos de subjetividade fragmentada: é preciso dividir para dominar. Isto é bem visível nas práticas de escolarização conservadora tendentes a priorizar alguns aspectos cognitivos e morais em detrimento do desenvolvimento integral. A fragmentação aqui mencionada, sempre parcial, ocorre em dois planos: a divisão interna no eu da criança, que aprende a negar sentimentos, sensações e percepções; e a divisão entre o eu e a realidade.

Mas como promover os processos de formação integral? Ou, ainda, como fortalecer nas próprias práticas existentes os aspectos integradores que elas já têm? - pois não há uma prática totalmente integral (ou completamente fragmentadora). Podemos avançar mais se pensarmos o trabalho educativo em diferentes graus de integralidade. Aqui serão expostos algumas condições ou princípios tendencialmente favoráveis a essa qualidade. O primeiro é a integração, na própria prática educativa, entre o pensamento, o desejo e a ação da criança. Esta é uma característica que favorece a formação integral, pois tal associação promove a estruturação do eu de forma integrada e concentrada, e não dispersiva.

Uma outra condição favorável é que as práticas promovam a restauração do contato com a experiência corporal da criança ou preservem este contato original, se ele não foi afetado. O comprometimento desse contato é, em geral, conseqüência da introjeção de valores e orientações conflitantes com o que a criança realmente sente e percebe. Ela passa então a negar seus sentimentos e percepções. Este processo ocorre por pressão externa e por um esforço da própria criança para ser aceita pelos adultos. Esta fragmentação do eu - entre experiência corporal e comportamento observável e, mais tarde, entre experiência e pensamento - promove a fragmentação entre o eu e o contexto, pois a principal base de contato com a realidade concreta é o corpo.

Inversamente, a utilização da experiência como fundamento da aprendizagem permite que a criança não fique à mercê da ideologia (no sentido de falsa consciência), pois a experiência possibilita à criança dispor de uma base sensorial-consciente para questionar os valores morais que lhe são apresentados. Esta base de contato corporal com a realidade permite a escolha de valores de forma mais consciente e própria. Ela encontra, na sua experiência, uma importante referência para avaliar aquilo que lhe é proposto. É precisamente por isto que os modelos conservadores de escolarização negam ou oprimem a liberdade corporal e a sensualidade.

Na dimensão metodológica, o problema central para uma formação integral reside na separação entre métodos, currículos e fins, de um lado, e os desejos, necessidades e interesses da criança, de outro. Tal cisão leva à dissipação de energia e a hábitos através dos quais ela aprende a ocultar ou negar dimensões do seu ser, para conseguir sobreviver no ambiente pedagógico. É necessário, portanto, superar esta separação.

No aspecto mais íntimo da prática - a estruturação das atividades com as crianças é importante haver diversidade nas atividades, como tem ocorrido em muitas experiências escolares na educação infantil, muitas das quais pude acompanhar como orientador em projetos de extensão. Contudo, é importante 
acrescentar que, além da multiplicidade de atividades, estimulando diferentes aspectos da criança, é essencial que cada uma destas atividades possua: 1) riqueza e complexidade, jamais sendo rotineiras ou mecânicas; 2) conexão entre as várias atividades, para que não dispersem a formação da criança; 3) integração entre as atividades e os processos sociais que a criança vive, ou viverá em breve, fora da instituição.

Penso que precisamos superar a idéia, presente ainda em educação escolar e em alguns projetos na área de intervenção social, segundo a qual a realização do projeto e das atividades que ele propõe já constituem, em si e por si, efeitos educativos e sociais. Não creio que a atividade em si, necessariamente, consiga gerar mudanças subjetivas (embora toda mudança surja necessariamente de atividades e interações sociais ou pelo menos da reflexão provocada por estas atividades e interações).

Uma formação integral abrange o desenvolvimento de todos os aspectos possíveis da criança naquele momento. Isto só ocorrerá se as práticas de formação e a teoria que as fundamenta contemplarem todos os aspectos do ato educativo, sem estabelecer privilégios: o currículo, a qualidade das relações, o método, as condições materiais de trabalho, a satisfação das educadoras, os interesses e as necessidades infantis. Para produzir efeitos de formação integral, é preciso que as práticas sejam integrais, desde que não percam a sua identidade, o binômio aprendizagem-desenvolvimento.

Além disto, a constituição de tais práticas exige que as profissionais sejam bem integradas consigo mesmas e com a realidade; caso contrário, aspectos alienados do seu ser lhes dificultarão a percepção integral da criança e a capacidade para lidar com isto. A formação integral também depende sensivelmente de o trabalho coletivo ser bem integrado; senão, este trabalho dispersa a criança. Esta integração precisa ocorrer pelo menos em três níveis: entre todas as profissionais da instituição; entre as disciplinas, havendo um consistente projeto educativo interdisciplinar; e entre a instituição educativa e a comunidade externa, inclusive com ampla participação dos pais na estruturação do projeto educativo.

Em trabalhos como este estudo, se poderia pensar, como conclusão, pela identificação dos campos afetivos e de inserção e atuação social como os mais difíceis de trabalhar em nossa sociedade. Contudo, a questão se mostra mais complexa: todos os campos são difíceis de se desenvolver plenamente, inclusive o cognitivo - a menos que este seja reduzido à reprodução de fatos e conceitos, que não é a concepção aqui adotada. Ao contrário, o conhecimento como construção significativa e o pensar como reflexão poderosa e criativa, juntos com as outras habilidades mentais, se mostram tão complexos para o trabalho integral como a construção socioafetiva do eu ou o desenvolvimento das capacidades de atuação social. Isto acontece porque se trata de um só fenômeno: a formação humana plena.

Como conseqüência da conclusão anterior, decorre que só reduzindo de forma dramática o campo cognitivo é que se torna possível, na semiformação proporcionada pela escolarização em moldes tradicionais, estruturar práticas centradas no "cognitivo", isto é, trabalhar o conhecimento ao mesmo tempo que se oprime ou subdesenvolve as dimensões afetivas e de atuação social. Isto seria impossível se o campo cognitivo fosse trabalhado de forma plena, não porque as outras dimensões sejam conseqüência do campo cognitivo, mas porque todos os campos estão interligados.

Talvez seja impossível evitar a questão da formação integral, porque a escola se relaciona, sempre, com todas as dimensões da criança. Qualquer prática se relaciona com o integral, pois é impossível se relacionar com uma parte apenas. Mesmo que de forma distorcida e alienada - ao privilegiar a aprendizagem conceitual em detrimento de uma compreensão mais ampla do objeto, por exemplo - , a relação é com a integralidade. A própria atitude de negar a integralidade, mesmo implicitamente, é uma forma de se relacionar com ela. Neste caso, nega-se aquilo que existe precisamente porque existe e não sabemos como lidar com ele. A criança é um todo, embora não completo, e está integralmente naquilo que vive e faz, ao menos até aprender a se dissociar para sobreviver.

Um outro fator, de origem teórica, com forte influência na formação das educadoras, precisa ser superado para contribuir na expansão dos processos de formação integral: trata-se do monismo de muitas teorias, isto é, a ênfase seletiva em apenas um aspecto do objeto analisado. A superação do monismo teórico é necessária porque ele torna difícil uma compreensão integral da criança, que contemple os vários aspectos de seu ser. Se o pensamento não é complexo, ele tem dificuldade para captar a complexidade do fenômeno que investiga. 


\section{Referências bibliográficas}

ADORNO, Theodor; HORKHEIMER, Max. Dialética do esclarecimento: fragmentos filosóficos. Rio de Janeiro: Zahar, 1985.

APPLE, Michael. Educação e poder. Porto Alegre: Artes Médicas, 1989.

APPLE, Michael; BEANE, James. Escolas democráticas. São Paulo: Cortez, 1997.

COLL, César. O construtivismo na sala de aula. São Paulo: Ática, 1996.

COULON, Alain. Etnometodologia e educação. Petrópolis: Vozes, 1995.

DEWEY, John. Mi credo pedagógico. Buenos Aires: Losada, 1944.

. El hombre y sus problemas. Buenos Aires: Editorial Paidós, 1952.

. Como pensamos. São Paulo: Nacional, 1953.

. Reconstrução em filosofia. São Paulo: Nacional, 1958.

. Liberalismo, liberdade e cultura. São Paulo: Nacional, EDUSP, 1970.

1979a.

. Democracia e educação: introdução à filosofia da educação. São Paulo: Nacional, . Experiência e educação. São Paulo: Nacional, 1979b.

pensadores).

A criança e o programa escolar. São Paulo: Abril Cultural, 1980a. (Coleção os . Interesse e esforço. São Paulo: Abril Cultural, 1980b. (Coleção os pensadores).

. Experiência e natureza. São Paulo: Abril Cultural, 1980c. (Coleção os pensadores).

. Teoria da vida moral. São Paulo: Abril Cultural, 1980d. (Coleção os pensadores). pensadores).

Lógica: a teoria da investigação. São Paulo: Abril Cultural, 1980e. (Coleção os

. Pode a educação participar na reconstrução social? Currículos sem fronteiras. n.

2, p. 189-193, jul./dez. 2001. Disponível em: <www.curriculosemfronteiras.org>.

GALEFFI, Dante. Relações interpessoais: a construção dos sujeitos sociais autônomos e inventivos: estado da questão. Revista da FAEEBA, Salvador, v. 7, n. 9, p. 193-209, 1998.

. O que é isto: a fenomenologia? Uma introdução à concepção fenomenológica de Edmund Husserl. Salvador: FACED/UFBA, 1996. (não publicado).

GIROUX, Henry. Pedagogia radical: subsídios. São Paulo: Cortez, Autores Associados, 1983.

. Teoria crítica e resistência em educação: para além das teorias da reprodução. Petrópolis: Vozes, 1986. 
GIROUX, Henry. Praticando estudos culturais nas faculdades de educação. In: SILVA, Tomaz (Org.). Alienígenas na sala de aula: uma introdução aos estudos culturais em educação. Petrópolis: Vozes, 1995a.

Cultura popular e pedagogia crítica: a vida cotidiana como base para o conhecimento curricular. In: SILVA, Tomaz; MOREIRA, Flávio. Currículo, cultura e sociedade. São Paulo: Cortez, 1995b.

Professores como intelectuais: rumo a uma pedagogia crítica da aprendizagem. Porto Alegre: Artes Médicas, 1997.

GIROUX, Henry; McLAREN, Peter. Linguagem, escola e subjetividade: elementos para um discurso pedagógico crítico. Educação e Realidade, Porto Alegre, v. 18, n. 2, p. 21-35, jul./dez. 1993.

HEIDEGGER, Martin. Ser e tempo. Petrópolis: Vozes, 1989.

Sobre o "humanismo". São Paulo: Abril Cultural, 1979. (Coleção os pensadores).

MOGILKA, Maurício. Pensamento e desejo: práticas educativas e processos de formação humana em pleno capitalismo. Salvador: FACED/UFBA, 2004. Tese (Doutorado).

. O que é educação democrática? Contribuições para uma questão sempre atual. Curitiba: Editora da UFPR, 2003a.

Educar para a democracia. Cadernos de pesquisa. São Paulo, n. 119, p. 129-146, Fundação Carlos Chagas, 2003b. Disponível em: <www.scielo.br/pdf/cp/n119/ n119a07.pdf>.

Educação popular, subjetividade e intervenção democrática. Ágere Revista de Educação e Cultura, Salvador, n. 6, p. 113-130, 2002a.

Ensinar e educar: processos diferentes, mas não antagônicos. Teias Revista da Faculdade de Educação da UERJ, Rio de Janeiro, n. 5, p. 56-65, 2002b.

A pedagogia da experiência e sua importância em uma educação democrática. Educação em Revista, Belo Horizonte, n. 32, p. 85-102, dez. 2000.

NÓVOA, Antônio. Os professores e a sua formação. Lisboa: Dom Quixote, 1995.

PERRENOUD, Phillipe. Práticas pedagógicas, profissão docente e formação: perspectivas sociológicas. Lisboa: Dom Quixote, 1993.

PIAGET, Jean. Psicologia e pedagogia. Rio de Janeiro: Editora Forense, 1970. dores).

A epistemologia genética. São Paulo: Abril Cultural, 1978a. (Coleção os pensa-

Problemas de psicologia genética. São Paulo: Abril Cultural, 1978b. (Coleção os pensadores).

. Para onde vai a educação? Lisboa: Livros Horizonte, 1978c.

ROGERS, Carl. Liberdade para aprender. Belo Horizonte: Interlivros, 1978. 
ROGERS, Carl. Liberdade de aprender em nossa década. Porto Alegre: Artes Médicas, 1985.

. Um jeito de ser. São Paulo: EPU, 1983.

. Tornar-se pessoa. São Paulo: Martins Fontes,1991.

. Sobre o poder pessoal. São Paulo: Martins Fontes, 1992.

ROUSSEAU, Jean-Jacques. Do contrato social: princípios de direito político. São Paulo: Abril Cultural, 1978a. (Coleção os pensadores).

. Discurso sobre a origem e os fundamentos da desigualdade entre os homens. São Paulo: Abril Cultural, 1978b. (Coleção os pensadores).

. Emílio ou da educação. São Paulo: Martins Fontes, 1995.

SACRISTÁN, Gimeno; PÈREZ GÒMEZ, Andrés. Compreender e transformar o ensino. Porto Alegre: Artmed, 1998.

SCHOM, Donald. Formando professores reflexivos. In: NÓVOA, Antônio. Os professores e sua formação. Lisboa: Dom Quixote, 1995.

SOLÉ, Isabel. Disponibilidade para aprendizagem e sentido da aprendizagem. In: COLL, César. O construtivismo na sala de aula. São Paulo: Ática, 1996.

ZABALA, Antoni. A prática educativa: como ensinar. Porto Alegre: Artes Médicas, 1998.

ZEICHNER, Ken. Novos caminhos para o practicum: perspectivas para os anos 90. In: NÓVOA, Antônio. Os professores e sua formação. Lisboa: Dom Quixote, 1995.

Maurício Mogilka, doutor em Educação pela Faculdade de Educação da Universidade Federal da Bahia (UFBA), é professor de Metodologia do Ensino do Departamento de Educação da Universidade do Estado da Bahia (Uneb), Campus Salvador. Desenvolve trabalhos na área de educação, desenvolvimento humano e cidadania. Atua na extensão universitária, junto a movimentos sociais, ONGs e projetos comunitários.

mmogilka@uneb.br

\section{Abstract}

The human formation in the horizon of integrality

This article shows the subject, the methodology and the outcomes of a research recently concluded. The subject of this research was the whole process of education of the person. Although the several teaching theoretical models of the XX century support the whole education, the methodological structure of this education is hard, in the theory and in practice. Is this hardness inherent to the educational practice? Is there need that the practice emphasizes one dimension in the child's education? This is the main subject of this research 
that was developed with the concepts of the humanist pedagogy, specially the thought of Rousseau, Dewey and Rogers.

Keywords: educational practice; subjectivity; whole education; democratic education; humanist pedagogy.

Recebido em 27 de abril de 2004.

Aprovado em 26 de agosto de 2005. 